\title{
INTERACTION OF ANTHRACYCLINE ANTIBIOTICS WITH BIOPOLYMERS VIII. BINDING PARAMETERS OF ACLACINOMYCIN A TO DNA
}

\author{
Ulrich Katenkamp, Eberhard Stutter, Ingeborg Petri, \\ Friedrich A. Gollmick and Hermann Berg \\ Academy of Sciences of the GDR, Central Institute of Microbiology \\ and Experimental Therapy, Department of Biophysical Chemistry, \\ DDR-69 Jena, GDR
}

(Received for publication April 13, 1983)

\begin{abstract}
The binding of aclacinomycin A to DNA was investigated spectrophotometrically under equilibrium conditions. The self-association behaviour of aclacinomycin $\mathrm{A}$ was identified as dimerization. Based on a model of overlapping potential binding sites the subsequent results were obtained: equilibrium constant of cooperative binding $K=(7.58 \pm 2.15) \times 10^{8} \mathrm{M}^{-1}$, size of a binding site $\alpha=3.98 \pm 0.14$ base pairs, cooperativity parameter $\sigma=0.12 \pm 0.10$. These parameters were compared with those of adriamycin, daunomycin, and iremycin to draw some conclusions regarding the structural specialities of aclacinomycin A.
\end{abstract}

The isolation and characterization of aclacinomycin A (ACM, aclarubicin, for chemical structure see Fig. 1) and several aclacinomycin analogues from Streptomyces galilaeus MA144-M1 have been carried out by the research groups of UMEZAWA, and of the Sanraku Ocean Co. ${ }^{1 \sim 6)}$. The mechanism of action of aclacinomycin A was originally investigated in the laboratory of TANAKA ${ }^{7,8)}$.

$\mathrm{ACM}$ has potent antitumor activity against various experimental tumors coupled with a low cardiotoxicity ${ }^{3,4)}$ and a fast cellular uptake ${ }^{9}$.

From biochemical evidence of the inhibition of DNA-, RNA-, and protein synthesis DI MARCo et al. ${ }^{10)}$ at first concluded that the cancerostatic activity of anthracyclines - having basic sugar residues is caused by their affinity to form complexes with DNA. Nevertheless other cellular targets are known, e.g., membranes responsible for cytotoxicity ${ }^{11,12)}$.

Subsequent to the early binding studies ${ }^{10}$ ) on anthracyclines, their interactions and reactions with DNA have been investigated widely from the thermodynamic, kinetic and structural points of view $^{8,13 \sim 22)}$.

Because Matsuzawa et al..$^{5)}$ have shown that $\mathrm{ACM}$ is more effective in the inhibition of DNA- and RNA-synthesis in vitro than anthracyclines with monosaccharides, e.g., adriamycin (ADM, doxorubicin) and daunomycin (DAM, daunorubicin), we have investigated the binding of ACM to DNA according to a more appropriate model ${ }^{15)}$ in order to compare the equilibrium binding parameters with those of ADM, DAM and iremycin (IRM), which were determined recently ${ }^{15 \sim 18)}$.

Fig. 1. Structural formula of aclacinomycin A.

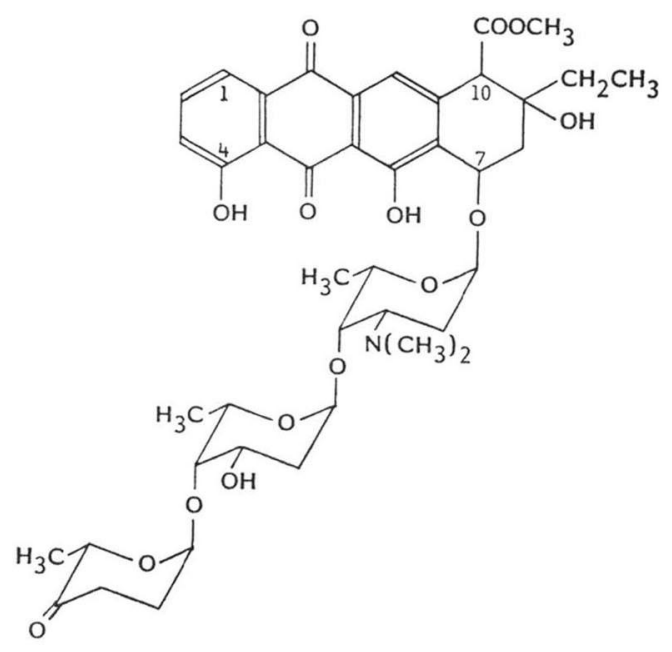




\section{Experimental and Theoretical Details}

Substances

ACM was kindly provided by Prof. H. Umezawa, Institute of Microbial Chemistry, Tokyo. Because ACM solutions were found to be very light-sensitive (its absorbance at $\nu=23,000 \mathrm{~cm}^{-1}$ is diminished to about 50 percent after exposure to day light of different intensities within 15 minutes to several hours) ACM solutions were kept in the dark. Calf-thymus DNA was prepared by SARFERT (Dept. of Mol. Biochemistry of our institute) and extensively dialyzed against McIlvaine buffer ( $\mathrm{pH}$ 6.0, ionic strength: $0.2 \mathrm{M}$ ) prior to the spectrophotometric measurements. All measurements were carried out at $25^{\circ} \mathrm{C}$.

\section{Method}

For the determination of ACM-DNA binding parameters spectrophotometric measurements were performed with the microcomputer-controlled spectrophotometer Specord M 40 (VEB Carl Zeiss, Jena). The absorbances $\mathrm{A}$ were recorded and printed at nine selected wavenumbers. All measurements were performed with the titration technique described by ScHütz et al. ${ }^{15)}$.

\section{Theoretical Analysis}

Matrix-rank analysis was applied to determine the number of spectroscopically independent components. Both the parameters of association and binding parameters were estimated with the curvefitting program ALAU (by H. Schürz from our institute). The data consistency of the binding measurements was checked by means of a model-free analysis, see GATTI et al. ${ }^{23)}$. The binding experiments were evaluated according to a single-step-binding-mechanism model of overlapping potential binding sites with nearest neighbour interaction among bound ligands ${ }^{24}$, DNA is considered a linear homogeneous and infinite chain. This model was extended taking into account self-association of ACM into dimers. For illustration of the binding data binding isotherms were constructed. The binding isotherm was plotted as $\mathrm{r} v s . \mathrm{c}_{\mathrm{m}}$ ( $\mathrm{r}$ : number of ligands bound per base pair, $\mathrm{c}_{\mathrm{m}}$ : concentration of free monomeric ligands). For further details concerning data analysis see ScHürz et al. ${ }^{15}$ ).

\section{Results}

\section{Self-association}

Recently the tendency of several anthracyclines to form aggregates in solution ${ }^{15 \sim 17,25,26)}$ has been shown. Therefore the concentration dependence of absorption spectra of ACM-buffer solutions was investigated in the range of $3 \times 10^{-7} \mathrm{M}$ to $6 \times 10^{-4} \mathrm{M}$. In Fig. 2 the apparent extinction coefficient $\varepsilon_{\mathrm{app}} v s$. the logarithm of the total ACM concentration $\mathrm{c}_{\mathrm{t}}$ is shown. The apparent extinction coefficient $\varepsilon_{\mathrm{app}}$ decreases at higher concentrations, i.e., ACM also shows self-association. The results of the matrixrank analysis indicate the occurrence of a pure monomer-dimer equilibrium. The dimerization parameters $\varepsilon_{\mathrm{m}}, \varepsilon_{\mathrm{d}}$ (extinction coefficients of monomers and dimers) and $K_{\mathrm{d}}$ (equilibrium constant of dimerization) are listed in Table 1. The extinction coefficients of monomers and dimers are comparable with those of $\operatorname{IRM}^{17)}, \mathrm{ADM}^{16)}$, and $\mathrm{DAM}^{15)}$, whereas $K_{\mathrm{d}}$ is significantly smaller. With the parameters from Table 1 the full lines in Fig. 2 were calculated. At low concentrations hints for cell-wall adsorption of the drug exist. However, the corresponding effects ${ }^{15)}$ were neglected in the further evaluations.

\section{Binding Parameters}

The binding parameters $K$ (cooperative equilibrium constant in the single contiguous case, corresponds to $K \omega$ in the nomenclature of MCGHEE and vON HIPPEL ${ }^{27)}$ ), $\sigma$ (cooperativity parameter after ZIMM and $\mathrm{BRAGG}^{28)}$ ), $\alpha$ (number of base pairs per bound ligand) and $\varepsilon_{\mathrm{b}}$ (extinction coefficient of the complex) were obtained from titrations according to the description in section 2 and are summarized in Table 2 . $K$ and $\alpha$ of ACM are significantly higher than the corresponding values of IRM, DAM, and ADM. 
Fig. 2. Apparent extinction coefficient $\varepsilon_{\text {app }}$ versus the logarithm of the total aclacinomycin concentration $c_{t}$ at two different wave numbers (points: experimental values obtained by measurements in cells with a length $\mathrm{d}$ between $0.2 \sim 5 \mathrm{~cm}$, full lines: calculated with parameters of Table 1).

$\varepsilon_{\text {app }}$ is defined by $\varepsilon_{\text {app }} \equiv \mathrm{A} /\left(\mathrm{d} \mathrm{c}_{\mathrm{t}}\right)$.

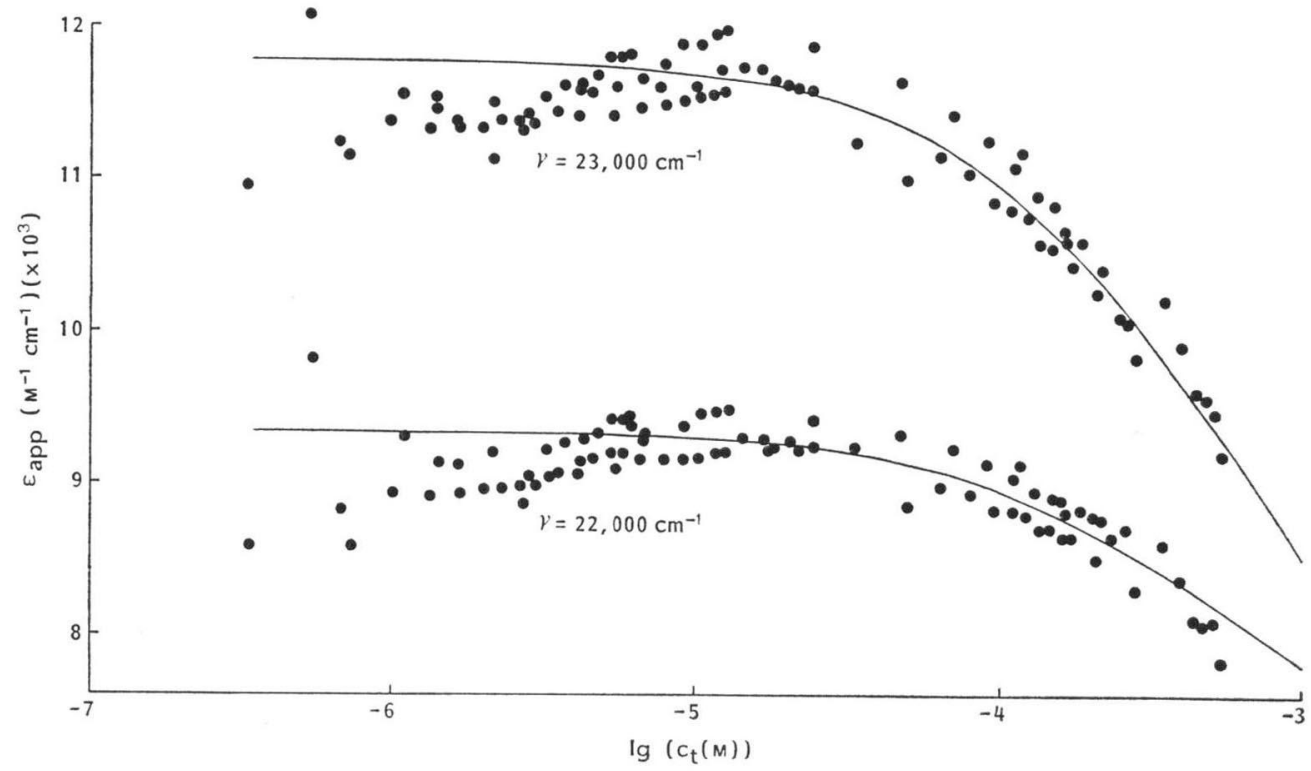

Table 1. Dimerization parameters of aclacinomycin

\begin{tabular}{|c|c|c|c|}
\hline \multirow{2}{*}{$\begin{array}{c}\text { Wave } \\
\text { number } \\
\left(\mathrm{cm}^{-1}\right)\end{array}$} & $\varepsilon_{\mathrm{m}}$ & $\varepsilon_{\mathrm{d}}$ & \multirow{2}{*}{$\underset{\left(\mathrm{M}^{-1}\right)}{K_{\mathrm{d}}}$} \\
\hline & \multicolumn{2}{|c|}{$\left(\mathrm{M}^{-1} \mathrm{~cm}^{-1}\right)$} & \\
\hline 22,000 & $9,328 \pm 19$ & $5,859 \pm 387$ & \\
\hline 23,000 & $11,769 \pm 21$ & $4,326 \pm 789$ & $120=122$ \\
\hline
\end{tabular}

Table 2. Equilibrium binding parameters of aclacinomycin A to DNA.

\begin{tabular}{lc}
\hline$K\left(\mathrm{M}^{-1}\right)$ & $(7.58 \pm 2.15) \times 10^{6}$ \\
$\sigma$ & $0.12 \pm 0.10$ \\
$\alpha$ (Base pairs) & $3.98 \pm 0.14$ \\
$\varepsilon_{\mathrm{b}}\left(\mathrm{M}^{-1} \mathrm{~cm}^{-1}\right)$ & $6,214 \pm 46$ \\
at $2=23,000 \mathrm{~cm}^{-1}$ & \\
\hline
\end{tabular}

WALTER et al. ${ }^{17}$ ) found, that in the region of drug concentrations lower than $1 /\left(200 K_{d}\right)$ the influence of the dimerization on the binding values is negligible. Because of the high binding constant $K$ and the low dimerization constant $K_{\mathrm{d}}$ compared with the corresponding constants of the other anthracyclines this condition was fulfilled for most of the test points. Thus, in contrast to other anthracyclines ${ }^{15 \sim 17)}$ the binding
Fig. 3. Binding isotherm of aclacinomycin $\mathrm{A}$ in comparison to the isotherms of adriamycin ${ }^{18)}$, daunomycin ${ }^{15)}$, and iremycin ${ }^{17)}$.

For the computation of the binding isotherms the following binding parameters are used (presumed that $\alpha$ is an integer ${ }^{22)}$ ):

\begin{tabular}{lccc}
\hline & $K\left(\mathrm{M}^{-1}\right)$ & $\sigma$ & $\begin{array}{c}\alpha \\
\text { (Base } \\
\text { pairs) }\end{array}$ \\
\hline Adriamycin & $(2.3 \pm 0.2) \times 10^{6}$ & $0.64 \pm 0.13$ & 3 \\
Daunomycin & $(7.1 \pm 0.5) \times 10^{5}$ & $0.98 \pm 0.04$ & 3 \\
Iremycin & $(2.3 \pm 0.5) \times 10^{5}$ & $0.58 \pm 0.07$ & 3 \\
Aclacinomycin & $(7.5 \pm 2.0) \times 10^{6}$ & $0.11 \pm 0.04$ & 4 \\
A (see Table 2) & & & \\
\hline
\end{tabular}

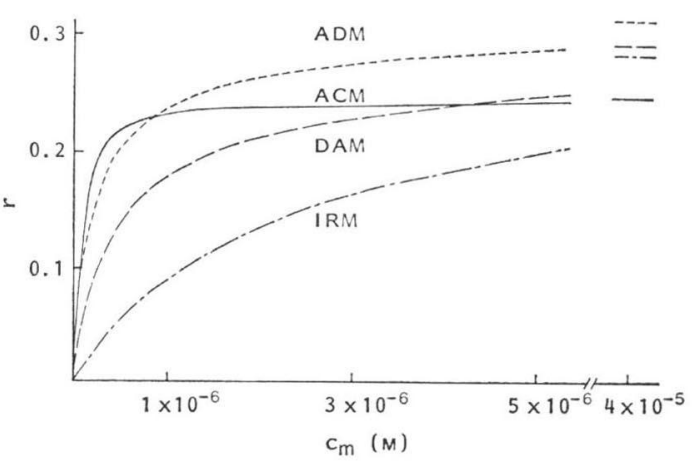


parameters are changed by only $\leq 10$ percent if the dimerization is disregarded. The cooperativity parameter $\sigma$ is markedly smaller than unity, i.e., related to other anthracyclines (see the legend from Fig. 3) the formation of bound ligand clusters is more probable than the binding of isolated ligands.

Thus the trisaccharide $\mathrm{ACM}$ shows several new aspects regarding $K, \alpha$, and $\sigma$.

\section{Discussion}

To compare the results from Table 2 with the binding parameters of IRM, DAM, and ADM the computed binding isotherms of the four anthracyclines are used (Fig. 3). OKI et al. ${ }^{4}$ ), CROOKE et al. ${ }^{2 \theta)}$, and Misumi et al. ${ }^{8}$ published, that the size of an ACM binding site runs to about three base pairs as in case of IRM, DAM, and ADM. In contrast to this we have found a size of a binding site of four base pairs for ACM as can be seen also from Fig. $3\left(\mathrm{r}_{\max }=1 / \alpha\right)$. This may be due to the fact, that the sugar chain of ACM is longer (trisaccharide) than those of the other three anthracyclines (monosaccharides). It is commonly accepted that their chromophores are intercalated between adjacent nucleotide bases of the DNA. On the other hand the sugar chain of the intercalated ACM is relatively flexible and possibly covers several potential intercalation sites. From the standpoint of mechanical inhibition mechanism ${ }^{10}$ ) of DNA- and RNA-synthesis a larger binding site may be more favourable than a smaller one since a certain degree of DNA-coverage requires a smaller number of drug molecules.

The relation between the magnitudes of the cooperative binding constants of IRM, DAM, and $\mathrm{ADM}$ is given by $K_{\mathrm{IRM}}<K_{\mathrm{DAM}}<K_{\mathrm{ADM}}$. However, the new antibiotic ACM binds even more strongly than ADM to DNA in the series as mentioned above. In this connection DUVERNAY et al. ${ }^{20)}$ and BERG et al. ${ }^{14}$ ) found that the longer the glycosidic side chain the higher the DNA binding affinity. Responsible for strong binding are at least the combination of three types of interaction: the electrostatic forces between the basic sugar and negative phosphate groups, the stacking forces ${ }^{14,20)}$ for the intercalated part of the chromophore, and the hydrogen bonds between sugar residues and bases. Consequently steffimycin with one "neutral" sugar forms a weaker complex whereas the aglycones show the weakest interactions $^{14,30)}$ and also no longer have biological activity.

The sequence of the binding constants $K_{\mathrm{IRM}}<K_{\mathrm{DAM}}<K_{\mathrm{ACM}}$ is valid also in presence of proteins as shown from FRITZSCHE et al. ${ }^{31}$ in case of the binding to 145 base-pair nucleosomes. Moreover, it should be noted that ACM inhibits DNA-synthesis in an in vitro polymerase system more strongly than the other three anthracyclines ${ }^{32)}$, as well as the growth, DNA- and RNA- synthesis of L1210 leukemia cells ${ }^{5)}$.

Moreover $\sigma$ of ACM is markedly smaller than that for IRM, DAM and ADM. All these differences must be due to structural changes at positions $\mathrm{C}-10, \mathrm{C}-11, \mathrm{C}-13$ of the chromophore and to the two additional neutral sugars. These peculiarities are responsible also for other metabolic pathways ${ }^{3,4)}$ and chemical behavior ${ }^{2,8,33)}$.

In conclusion, ACM is an anthracycline ligand type which exhibits in relation to IRM, DAM, ADM a smaller dimerization constant, a greater constant of cooperative binding to DNA, a smaller cooperativity parameter and a greater size of a binding site. The synergistic cooperation of these results plays an attractive role in the investigation and explanation of the molecular mechanisms of drug-DNA interaction. Our interaction results give more insight into the molecular properties of ACM and consequently to its biological behavior.

\section{Acknowledgments}

We wish to thank Prof. H. UmEZAWA (Tokyo) not only for the gift of aclacinomycin A but also for valuable suggestions. The fruitful discussions with the Drs. H. Fritzsche, K. E. ReInert, W. Förster, H. TrIebel, and A. WALTER are gratefully acknowledged.

\section{References}

1) OKi, T.; Y. Matsuzawa, A. Yoshimoto, K. Numata, I. Kitamura, S. Hori, A. Takamatsu, H. Umezawa, M. IshizuKa, H. NAGANAWA, H. SUdA, M. HAMADA \& T. TAKeUCHI: New antitumor antibiotics, aclacino- 
mycins A and B. J. Antibiotics 28: 830 834, 1975

2) Oki, T.; I. Kitamura, A. Yoshimoto, Y. Matsuzawa, N. Shibamoto, T. Ogasawara, T. Inui, A. Takamatsu, T. Takeuchi, T. Masuda, M. Hamada, H. Suda, M. Ishizuka, T. Sawa \& H. Umezawa: Antitumor anthracycline antibiotics, aclacinomycin A and analogues. I. Taxonomy, production, isolation and physicochemical properties. J. Antibiotics 32: $791 \sim 800,1979$

3) Hori, S.; M. Shirai, S. Hirano, T. Oki, T. Inui, S. Tsukagoshi, M. Ishizuka, T. Takeuchi \& H. Umezawa: Antitumor activity of new anthracycline antibiotics, aclacinomycin A and its analogs, and their toxicity. Gann 68: 685 690, 1977

4) OKI, T.; T. TAKeuchi, S. OKa \& H. Umezawa: New anthracycline antibiotic aclacinomycin A: Experimental studies and correlation with clinical trials. Rec. Res. Canc. Res. 76: $21 \sim 40,1981$

5) Matsuzawa, Y.; T. OKI, T. TAKeUchi \& H. Umezawa: Structure-activity relationships of anthracyclines relative to cytotoxicity and effects on macromolecular synthesis in L1210 leukemia cells. J. Antibiotics 34: $1596 \sim 1607,1981$

6) Oki, T.; I. Kitamura, Y. Matsuzawa, N. Shibamoto, T. Ogasawara, A. Yoshimoto, T. Inui, H. NagaNAWA, T. TAKeUCHI \& H. UmezaWA: Antitumor anthracycline antibiotics, aclacinomycin A and analogues. II. Structural determination. J. Antibiotics 32: 801 819, 1979

7) Yamaki, H.; H. Suzuki, T. Nishimura \& N. Tanaka: Mechanism of action of aclacinomycin A. I. The effect on macromolecular syntheses. J. Antibiotics 31: 1149 1154, 1978

8) Misumi, M.; H. Yamaki, T. Akiyama \& N. Tanaka: Mechanism of action of aclacinomycin A. II. The interaction with DNA and with Tubulin. J. Antibiotics 32: $48 \sim 52,1979$

9) Egorin, M. J.; R. E. Clawson, L. A. Ross, N. M. Schlossberger \& N. R. Bachur: Cellular accumulation and disposition of aclacinomycin A. Canc. Res. 39: 4396 4400, 1979

10) Calendi, E.; A. di Marco, M. Reggiani, B. Scarpinato \& A. Valentini: On physico-chemical interaction between daunomycin and nucleic acids. Biochim. Biophys. Acta 103: $25 \sim 49,1965$

11) Tritton, T. R. \& G. Yee: The anticancer agent adriamycin can be actively cytotoxic without entering cells. Science 217: 248 250, 1982

12) Myers, Ch. E.: Antitumor antibiotics I: Anthracyclines. Cancer Chemotherapy 1980. Ed. PINedo, H. M., pp. 66 89, Experta Medica, Amsterdam Oxford, 1980

13) NeIdle, S.: The molecular basis for the action of some DNA-binding-drugs. Progress in Medicinal Chemistry. 16. Ed., G. P. Ellis \& G. B. WeST, pp. $151 \sim 221$, Elsevier/North-Holland Biomedical Press, 1979

14) Berg, H.; G. Horn, U. LuthardT \& W. IHN: Interaction of anthracycline antibiotics with biopolymers. V. Polarographic behaviour and complexes with DNA. Bioelectrochem. Bioenerg. 8: 537 553, 1981

15) Schütz, H.; F. A. Gollmick \& E. Stutter: Determination of the equilibrium binding parameters of daunomycin to DNA. Studia Biophysica 75: 147 159, 1979

16) Stutter, E.; F. A. Gollmick \& H. Schütz: Interaction of anthracycline antibiotics with biopolymers. IV. The binding of adriamycin to DNA under equilibrium conditions. Studia Biophysica 88: 131 138, 1982

17) Walter, A.; H. Schütz \& E. Stutter: Interaction of anthracycline antibiotics with biopolymers. VII. Parameters of binding of the new antibiotic iremycin to DNA. Int. J. Biol. Macromol., in press

18) Chaires, J. B.; N. Dattagupta \& D. M. Crothers: Studies on the interaction of anthracycline antibiotics and DNA: Equilibrium binding studies on the interaction of daunomycin with DNA. Biochemistry 21: $3933 \sim 3940,1982$

19) Fritzsche, H.; H. Triebel, J. B. Chaires, N. Dattagupta \& D. M. Crothers: Studies on the interaction of anthracycline antibiotics and DNA: Geometry of intercalation of iremycin and daunomycin. Biochemistry 21: 3940 3946, 1982

20) DuVernay, Jr., V. H.; J. A. Pachter \& S. T. Crooke: Deoxyribonucleic acid binding studies on several new anthracycline antitumor antibiotics. Sequence preference and structure-activity relationships of marcellomycin and its analogues as compared to adriamycin. Biochemistry 18: 4024 4030, 1979

21) Arcamone, F.; E. Arlandini, M. Menozzi, L. Valentini \& E. Vannini: Doxorubicin and related compounds. I. Physico-chemical characterization of the DNA complex. In Anthracycline Antibiotics in Cancer Therapy. Ed. F. Muggia, C. Young \& S. CARTer, Developments in Oncology 10, Martinus Nijhoff Pub., in press

22) Förster, W. \& E. StUtTer: Interaction of anthracycline antibiotics with biopolymers. IX. Interaction kinetics of daunomycin, adriamycin, and iremycin with DNA. Int. J. Biol. Macromol., submitted

23) Gatti, C.; C. Houssier \& E. FredericQ: Binding of ethidium bromide to ribosomal RNA. Absorption, fluorescence, circular and electric dichroism study. Biochim. Biophys. Acta 407: 308 319, 1975

24) Bradley, D. F. \& S. Lifson: Statistical mechanical analysis of binding of acridines to DNA. In Mole- 
cular Associations in Biology. Ed. B. Pullman, pp. $261 \sim 270$, Acad. Press Inc. New York, 1968

25) Chaires, J. B.; N. Dattagupta \& D. M. Crothers: Self-association of daunomycin. Biochemistry 21 : $3927 \sim 3932,1982$

26) Martin, S. R.: Absorption and circular dichroic spectral studies on the self-association of daunorubicin. Biopolymers 19: 713 721, 1980

27) McGhee, J. D. \& P. H. von Hippel: Theoretical aspects of DNA-protein interactions: Co-operative and non-co-operative binding of large ligands to a one-dimensional homogeneous lattice. J. Mol. Biol. 86: $469 \sim 489,1974$

28) Zimm, B. H. \& J. K. BrAGG: Theory of the phase transition between helix and random coil in polypeptide chains. J. Chem. Phys. 31: 526 535, 1959

29) Crooke, S. T.; V. H. Duvernay \& S. Mong: Molecular pharmacology of anthracyclines. In Molecular Actions and Targets for Cancer Chemotherapeutic Agents. pp. $137 \sim 162$, Academic Press Inc., 1981

30) Löber, G.; V. Kleinwächter, Z. Balcarova, R. Klarner \& W. Fleck: Interaction of violamycin antibiotics with nucleic acids. II. Spectroscopic evidence for the binding of violamycin BI to deoxyribonucleic acid (DNA). Studia Biophysica 71: 205 206, 1978

31) Fritzsche, H.; J. B. Chaires, N. Dattagupta \& D. M. Crothers: Interaction of anthracycline antibiotics to DNA and nucleosomes, a comparative study. Studia Biophysica 92: 67 68, 1982

32) WähNERT, U.: Anthracyclines as inhibitors of DNA synthesis in vitro. Studia Biophysica 92: 65 66, 1982

33) Berg, H.; G. Horn \& W. IHN: Electrochemical reduction pathways of anthracycline antibiotics. J. Antibiotics 35: $800 \sim 805,1982$ 